\title{
Ordering and the micromechanics of Ti-7Al
}

\author{
Anna Radecka ${ }^{\mathrm{a}}$, James Coakley ${ }^{\mathrm{b}, \mathrm{c}}$, Ian P Jones ${ }^{\mathrm{d}}$, David Rugge, Trevor \\ Lindley $^{\mathrm{a}}$, David Dye ${ }^{\mathrm{a}}$ \\ ${ }^{a}$ Department of Materials, Royal School of Mines, Imperial College London, Prince Consort \\ Road, London, SW7 2BP, UK \\ ${ }^{b}$ Department of Materials Science and Metallurgy, University of Cambridge, Cambridge, \\ CB3 OF3, UK \\ ${ }^{c}$ Northwestern University, Department of Materials Science and Engineering, 2220 Campus \\ 6 Drive, Evanston, IL 60208-3108, USA \\ ${ }^{d}$ School of Metallurgy and Materials, University of Birmingham, Birmingham, B15 2TT, \\ $U K$ \\ ${ }^{e}$ Rolls Royce, Elton Road, Derby, DE24 8BJ, UK
}

\begin{abstract}
The evolution of intergranular lattice strain in the $\alpha$ titanium alloy Ti-7Al wt.\% was characterised using in situ time-of-flight (TOF) neutron diffraction during room temperature tensile loading. Samples were aged to promote ordering and the formation of nanometre-scale $\alpha_{2}\left(\mathrm{Ti}_{3} \mathrm{Al}\right)$. On ageing, at $550^{\circ} \mathrm{C}$ and $625^{\circ} \mathrm{C}$, dislocations were observed to travel in pairs, and in planar arrays, which has been attributed to the presence of ordering. A slight change in $c / a$ was observed, from 1.6949 to 1.6945 , and a slight increase in the macroscopic modulus. However, no changes were observed in the residual lattice strains, which are the grain-orientation average elastic strains produced by plasticity. Therefore it is inferred that the changes in deformation mechanisms caused by ordering that result in an enhanced vulnerability to dwell fatigue affect primarily the extent of slip localisation. The overall strain distributions between grains in different orientations is not changed.
\end{abstract}

Keywords: Titanium alloys, neutron scattering, ordering,

\section{Introduction}

Curently, about half of the world production of titanium is used in the aerospace industry 1, 2, 3, 4, 5. Principally, Ti alloys are favoured for their good specific high cycle fatigue strength, modulus compatibility with carbon 5 fibre composites and corrosion resistance [6, 7, 8]. There is a longstanding concern about the response of near- $\alpha$ and $\alpha / \beta$ titanium alloys to cold dwell fatigue conditions (cyclic loading with holds at load at room temperature) 9 . Most commercial titanium alloys are alloyed with around $6 \mathrm{wt} . \%$ Al. Since the

${ }^{*}$ Corresponding Author. Email david.dye@imperial.ac.uk, Tel: +44 7977076141 (no fax).

Preprint submitted to Materials Science and Engineering A

May 8, 2015

(C) 2015. This manuscript version is made available under the Elsevier user license http://www.elsevier.com/open-access/userlicense/1.0/ 
1960s it has been known that the $\alpha$ phase in Al-containing Ti alloys undergoes ordering during prolonged thermal exposure at temperatures around $500^{\circ} \mathrm{C}$ and the precipitation of fine, $10 \mathrm{~nm}$ islands of the ordered $\mathrm{Ti}_{3} \mathrm{Al} \alpha_{2}$ phase [10, 11, 12.

According to Namboodhiri [13, $\alpha$-Ti can chemically order when aged at temperatures around $500-700^{\circ} \mathrm{C}$, termed 'short range ordering' (SRO), without long length scale chemical rearrangement. This gives rise to the appearance 15 of diffuse spots in the electron diffraction patterns observed in the transmission electron microscope (TEM) [14] and very diffuse diffraction peaks observed using neutron diffraction at the correct positions for the $\alpha_{2}$ phase [12, 14, 15]. At lower temperatures, instead it is suggested that the material enters the $\alpha+\alpha_{2}$ two-phase field, such that a chemical spinodal-like decomposition can occur, as 20 suggested by Liew et al. (née Wood) [16, 17. A phase diagram summarising this is shown in Figure 1 (a).

Blackburn and Williams [18, observed a transition from homogenous to planar slip with increasing $\mathrm{Al}$ content. Since that time, ordering has been discussed as an important factor contributing to the anomalous solid-solution strength25 ening of Ti-Al system. It has been suggested, for example, that this leads to a requirement for dislocations to travel in pairs, as observed by Neeraj [15] and Blackburn and Williams [18. It was also observed that dislocations can only travel on every other plane [15, 18]. Therefore, it is suggested that this is the reason why intermediate temperature ageing, or even just slow cooling, so can render Al-containing near- $\alpha$ alloys and $\alpha / \beta$ alloys more dwell-susceptible. This may be of concern to gas turbine manufacturers for certain aero-engine components and load cycles. However, the factors promoting ordering (such as oxygen content), as well as its effect on the deformation mechanisms that underlie fatigue crack nucleation, growth and propagation, are still not fully understood. The present work aims to provide better understanding of how the ageing condition affects the micromechanics of Ti-7Al wt.\% (11 at.\%), which is close to the $\mathrm{Al}$ content of the isolated alpha phase in the majority of $\alpha / \beta$ titanium alloys in commercial use [7.

Recently, it has become popular to study the load partitioning between 40 grains in different orientations using in situ time-of-flight neutron diffraction [12, [19, 20, 21] or synchrotron X-ray diffraction (SXRD) [22, 23, 24]. These experiments measure the change in peak position for grains that satisfy the diffraction conditions, in response to a change in the macroscopic applied stress. This provides a so-called internal strain gauge that measures the average behaviour of 45 'families' of grains sharing a common diffraction plane in the loading direction. Together with TEM observations of the operative dislocation mechanisms, this allows a characterisation of the micromechanical behaviour of a material both at the individual dislocation length scale and at the level of grain averages.

In the present work, in situ time-of-flight (TOF) neutron diffraction mea50 surements were performed using the engineering materials diffractometer VULCAN at the Spallation Neutron Source (SNS), Oak Ridge National Laboratory (ORNL), TN, USA to characterise the loading response of Ti-7Al in different ageing conditions. This was accompanied by ex-situ TEM to characterise the deformation mechanisms. 


\section{Experimental Description}

[Figure 1 about here.]

Two ingots were prepared by vacuum arc melting and hot rolled to $13 \times$ $13 \mathrm{~mm}$ square bar at Timet Witton, Birmingham, UK. Commercial purity Ti sponge was used to obtain industrially representative Fe and Si contents, and 60 an $\mathrm{O}$ content of $1800 \mathrm{ppmw}$. The as-cast ingots were homogenised at $1125^{\circ} \mathrm{C}$ and then beta forged. $\beta$ phase profile rolling followed by $\alpha$ phase profile rolling as performed at $1125^{\circ} \mathrm{C}$ and $800^{\circ} \mathrm{C}$ respectively in order to reduce the ingots to the final dimensions over 9 passes, with two intermediate reheats. The rolled bar was then encapsulated within quartz with an Ar atmosphere and recrys-

65 tallised at $1125^{\circ} \mathrm{C}$ for $60 \mathrm{~min}$. The composition obtained was measured by inductively coupled plasma optical emission spectroscopy (ICP-OES) at Timet Savoie, France. The final microstructure is provided in Figure 1)(b); it is evident that a strong $\{11 \overline{2} 0\}$ rolling texture was produced, Figure 1(d).

$3 / 8$ " UNF threaded tensile specimens with a gauge diameter of $5.6 \mathrm{~mm}$ and $34 \mathrm{~mm}$ length were machined with the parallel specimen length along the rolling direction (RD). These were encapsulated within quartz with an Ar atmosphere and heat treated at $920^{\circ} \mathrm{C}$ for $10 \mathrm{~min}$ followed by:

- (IWQ) ice water quenching,

- (AC) air cooling,

- $(625 / 14) \mathrm{AC}$, then aged at $625^{\circ} \mathrm{C}$ for 14 days,

- $(550 / 28) \mathrm{AC}$, then aged at $550^{\circ} \mathrm{C}$ for 28 days.

Thus, the four conditions were intended to produce to progressively greater amounts of ordering.

The specimens were deformed in-situ in tension at the VULCAN diffractometer at the Spallation Neutron Source at ORNL in order to examine the effect of the different heat treatments on the load partitioning that occurs during plasticity. A detailed description of the instrument can be found elsewhere [25, 26, 27, 28, 29]. A schematic illustration of the experimental setup is shown in Figure 2(a).

[Figure 2 about here.]

Loading measurements were made at room temperature using an MTS servohydraulic testing machine and a $10 \mathrm{~mm}$ extensometer. Neutron diffraction measurements were first made at a pinch load of $20 \mathrm{MPa}$. In the fully elastic region, 13 measurements were made at intervals of $50 \mathrm{MPa}$ up to $620 \mathrm{MPa}$, at a loading

90 rate of $50 \mathrm{MPas}^{-1}$. Subsequently, through the elasto-plastic transition, increments of strain were applied at a strain rate of $3 \times 10^{-4} \mathrm{~s}^{-1}$, followed by a $5 \mathrm{~s}$ hold in strain control and then unloading to $620 \mathrm{MPa}$ at $50 \mathrm{MPa} \mathrm{s}^{-1}$. This was performed in order to minimise cold creep during extended holds whilst obtaining neutron diffraction patterns at the point of yield, without giving rise to yielding on unloading between grains in different orientations. The increment in strain applied was $0.45 \%$; approximately $0.20 \%$ of this strain was recovery of 
the elastic unload and $0.25 \%$ was the plastic strain increment. A 20 min sampling time was used. After approximately $4.5 \%$ plastic strain had been applied, the sample was unloaded at $50 \mathrm{MPas}^{-1}$ and a final measurement was made at $20 \mathrm{MPa}$.

The diffractometer was operated at $20 \mathrm{~Hz}$, taking one in three of the spallation neutron pulses from the target, with a central wavelength of $2.8 \AA$ and a bandwidth of $4.3 \AA$. Vulcan has detector banks at $\pm 90^{\circ}$, and peaks within a dspacing range of $0.46-3.0 \AA$ could be observed. $5 \times 5 \mathrm{~mm}$ incident slits were used with collimators focussed on a $5 \mathrm{~mm}$ wide region in the samples. Figure 2 (b) shows the indexed diffraction spectra for the IWQ specimen at the initial load of $20 \mathrm{MPa}$. Vulcan is the optimised for flux over the $0.7-1.2 \AA d$-spacing range, which corresponds to rather high order peaks in hcp $\alpha$-Ti. However, more than 15 distinct peaks could be observed. In this work, only the first order peaks are presented. Neutron diffraction data were collected and analysed for the $\{10 \overline{1} 0\}$ $\{10 \overline{1} 1\},\{11 \overline{2} 0\},\{11 \overline{2} 2\},\{20 \overline{2} 3\},\{20 \overline{2} 1\},\{21 \overline{3} 1\}$, and $\{21 \overline{3} 3\}$ peaks. The specimen texture modifies the observed intensities from those of an ideal powder, such that certain peaks may not be visible. For example, the specimen texture has very few $\{0002\}$-oriented grains in the rolling / loading direction, and hence 115 this peak was not detected in the longitudinal bank.

The original source spectra were analysed using the VDRIVE (VULCAN Data Reduction and Interactive Visualization software) software package [30. Each reflection was fitted individually using a single Gaussian peak; an example is shown in Figure 2(b).

${ }_{120}$ For each $\{h k i l\}$ peak analysed, the elastic lattice strain $\epsilon^{h k i l}$ was calculated from the relative change in measured d-spacing $d^{h k i l}$, using $\epsilon^{h k i l}=\left(d^{h k i l}-\right.$ $\left.d_{0}^{\text {hkil }}\right) / d_{0}^{\text {hkil }}$, where $d_{0}^{\text {hkil }}$ is a stress-free reference $\mathrm{d}$-spacing. This reference spacing was calculated from the 13 measurements comprising the linear response during the initial elastic loading to $620 \mathrm{MPa}$, which is a more accurate manner 125 to measure $d_{0}^{h k i l}$ than using a single value measured at zero load [21]. In this way, the apparent stiffness, or diffraction elastic constant (DEC), for each peak was also determined. Figure 3(a) shows an example of the evolution of macroscopic stress against lattice strain in the elastic regime for the $\{11 \overline{2} 0\}$ diffraction peaks for each heat-treatment studied.

${ }_{130}$ Samples for TEM examination were removed from the deformed specimens. Thin foils were prepared by mechanical grinding using SiC paper to a thickness of approximately $200 \mu \mathrm{m}$. Before final thinning, 3mm discs were electrodischarge machined. After cutting, each disc was further thinned by hand grinding to a thickness of approximately $120 \mu \mathrm{m}$. The discs were then electropolished using a solution consisting of $3 \%$ perchloric acid $\left(\mathrm{HClO}_{4}\right), 40 \%$ butan-1-ol $\left(\mathrm{C}_{4} \mathrm{H}_{10} \mathrm{O}\right)$ and $57 \%$ methanol $\left(\mathrm{CH}_{3} \mathrm{OH}\right)$. Electropolishing was undertaken at $40^{\circ} \mathrm{C}$ with an applied voltage of $25 \mathrm{~V}$. The specimens were examined in a JEOL 2000FX TEM with an Oxford Instruments ultra-thin window energy dispersive X-ray spectrometer (EDS) and in a JEOL 2010 TEM. A double tilt holder was 140 used for the determination of crystal structure and for diffraction analysis.

Electron backscatter diffraction (EBSD) was performed on a cross-section through the hot rolled bar, Figure 1. Samples were prepared by grinding and 
polishing using a mixture of colloidal silica and hydrogen peroxide $\left(\mathrm{H}_{2} \mathrm{O}_{2}\right)$. EBSD was conducted on a Zeiss Auriga SEM at $20 \mathrm{kV}$.

\section{Results and discussion}

[Figure 3 about here.]

The macroscopic stress-strain curves for the IWQ, AC, 625/14, and 550/28 conditions are shown in Figure 3(b). All four specimens showed an essentially identical loading response, with a yield stress of $\sim 800 \mathrm{MPa}$ and very little work hardening. However, a progressive rise in the macroscopic Young's modulus with ageing could be observed, Table 2, from 105 to $114 \mathrm{GPa}$.

[Table 1 about here.]

The Millers-Bravais indices of the $\{11 \overline{2} 0\}$ and $\{10 \overline{1} 2\}$ peaks and their $d_{0}$ values were used to determine the lattice parameters $(c$ and $a)$. The calculated $c / a$ ratios are shown in Table 2, whilst the measured $d_{0}^{h k i l}$ and diffraction elastic constants (DECs) as a function of the orientation parameter $H^{2}$ are shown in Table 1. $H^{2}$ represents the cosine of the angle between a plane $\{$ hkil $\}$ and the basal plane [31.

The DECs are a consequence of the stiffness of the underlying grains and their orientations, with accommodation by the surrounding grain environment. For hexagonal single crystals, the Young's modulus varies linearly with $H^{2}$.

Generally, a slight reduction in the measured $d_{0}$ values was observed with ageing, by a factor of between $6.7 \times 10^{-4}$ for the $\{10 \overline{1} 0\}$ and $4.1 \times 10^{-4}$ for the $\{20 \overline{2} 3\}$. The exception was the $\{20 \overline{2} 1\}$, which was the peak with the worst peak fitting uncertainty. Similarly, a trend in reduction of $c / a$ with ageing could be observed, except for the $550 / 28$ sample where $\alpha_{2}$ precipitation was intended.

However, the DEC values show almost no variation, despite the around $10 \%$ increase in the macroscopic modulus, and despite the very low measured uncertainties (again, with the exception of the $\{20 \overline{2} 1\}$ peak). This suggests that the stiffer $\alpha_{2}$ phase increased the specimen stiffness without affecting the strains in the $\alpha$ matrix. This observation is still not fully understand and needs more detailed studies.

During the elastic-plastic transition, depending on the orientation with respect to the tensile axis, some grains accumulate plastic strain whereas others 175 deform elastically [32, 33. This results in a transfer of load to grains in stronger orientations, which progresses until all the grains have begun to yield. Deformation initially occurs in grains oriented favourably for slip (also called soft grains [21]), with elastic strain partitioning to the grains oriented unfavourably for slip. As a result, on unloading, residual microstresses remain within the grains that are last to deform. These internal elastic strains varying between grains are termed intergranular strains [21, 32].

[Figure 4 about here.] 
[Figure 5 about here.]

The evolution of the residual lattice strains with plastic strain for each sam185 ple is shown in Figure 4. These are additional lattice strains measured after subtracting the elastic lattice strains expected from the DEC's, and were measured during the holds at $620 \mathrm{MPa}$, thus avoiding both plasticity on unloading and cold creep. The peak with the lowest fitting uncertainty $(39 \mu \varepsilon)$, the $\{11 \overline{2} 0\}$, shows almost no variation between the specimens. It accumulates a net compressive residual lattice strain of between -190 and $-240 \mu \varepsilon$, which is very similar to the observation of $-200 \mu \varepsilon$ in $\mathrm{CP} \mathrm{Ti}$ 21. Similar behaviour is observed for the $\{21 \overline{3} 1\}$. The $\{10 \overline{1} 1\}$ and $\{11 \overline{2} 2\}$ both show an extended elasticplastic transition over the first $2 \%$ plastic strain, with load partitioning from these orientations to stronger orientations, and quite large residual microstrains 195 of $-800 \mu \varepsilon$. For reference, $1000 \mu \varepsilon$ would correspond, very approximately, to a stress of $110 \mathrm{MPa}$. It can also be observed that none of the specimen conditions results in a significant alteration in lattice strain response.

The trends observed are summarised in Figure 5 , which is an inverse pole figure of the measured residual lattice strains in the loading direction. The requirement for a stress balance implies that the residual lattice strains, when texture-weighted, must average to zero, so some orientations must possess positive residual elastic lattice strains - it just happens that these orientations were not accessible experimentally. The 'soft' orientations towards $\{10 \overline{1} 0\}$ and $\{11 \overline{2} 0\}$ all show small compressive residual lattice strains. The largest compressive microstrains are found at intermediate inclinations of the $c$-axis, since these are orientations where the prism planes are closest to the plane of maximum shear $\left(45^{\circ}\right)$. Therefore the positive residual strain must be found for grains that are orientated near-\{0001\}, which was the smallest texture component and could not be measured. These inferences are summarised in the contour lines drawn ${ }_{210}$ as a guide to the eye. When taking the average across the interval between 2 and $4 \%$ plastic strain, no statistically significant trends can be observed.

Compared to $\mathrm{CP} \mathrm{Ti}$ in a similar, bar rolled condition and deformed in tension [21, some systematic differences can be observed, due to the effect of the aluminium substitution. The $\{10 \overline{1} 0\}$ peak shows insignificant residual lattice strain accumulation, compared to $-2 \times 10^{-4}$ in CP Ti. The $\{10 \overline{1} 1\}$ and $\{11 \overline{2} 0\}$ show very similar, slightly compressive behaviour. And finally, the behaviour of the $\{11 \overline{2} 2\}$ and $\{20 \overline{2} 1\}$ is reversed, with the $\{11 \overline{2} 2\}$ showing compressive microstrains of around $-600 \mu \varepsilon$ and the $\{20 \overline{2} 1\}$ near-zero lattice strain accumulation. Thus, the most compressive microstrains appear to have been shifted to slightly higher $H^{2}$, to grains with $c$-axes slightly more inclined to the loading direction.

\subsection{Transmission Electron Microscopy (TEM) and Electron Backscatter Diffrac- tion (EBSD)}

The tensile test samples following $4.5 \%$ plastic strain were observed by TEM. Dislocation Burgers vectors were determined by $\mathrm{g} \cdot \mathrm{b}$ (b -Burgers vector) invisi225 bility analysis [34, 35, 36]. 
There was no evidence of ordering in the IWQ specimen, consistent with previous work on Ti-7Al (wt.\%) [37, 38. Progressively stronger superlattice reflections were observed in the specimens aged at $625^{\circ} \mathrm{C}$ for 14 days and specimens aged at $550^{\circ} \mathrm{C}$ for 28 days (Figure 6 (a-d)). In Ti-6Al-4V, sometimes weak superlattice reflections can be observed in material that has been air cooled [39], but these could not be observed in the present case.

The observation of superlattice spots implies long range order, achieved via a first transition (discrete particles with a different chemical composition) or via a second order transition (no change in chemical composition). However, clear field imaging using the superlattice spots, was not observed. Brandes et al. 37. made similar observations in both Ti-7Al and Ti-6Al-2Sn-4Zr-2Mo. Also, Liew et al. 40, 17 presented similar results in their study of the size and morphology of the ordered regions in Ti-15Al (at.\%) by electron microscopy and electron diffraction. Here, for heat treatments of less than 500 hours at $550{ }^{\circ} \mathrm{C}$ the superlattice reflections were too weak to produce an image.

[Figure 6 about here.]

[Figure 7 about here.]

As previously observed by Williams and Blackburn [18, Brandes [37] and Thirumalai 12, after heat treatment, the dislocation arrangements changed from isolated $\langle a\rangle$-type dislocations to $\langle a\rangle$ dislocations moving in bands, Figures 7 .9. So, for example, in the air cooled sample, the dislocations observed extend across the sample, extending from sources within the grain. Dislocations can also be observed to glide over each other, and extend across the sample. In contrast, in the sample aged into the $\alpha+\alpha_{2}$ region of the Ti-Al phase diagram (according to Namboodhiri [13), Figure 9, the dislocations travel in distinctive bands, and group into pairs, as first observed by Blackburn and Williams [18]. This behaviour is also characteristic of deformation in the presence of hydrogen, e.g. during stress corrosion cracking. This has been widely attributed to 255 the requirement for $\alpha$-Ti dislocations to travel in pairs in ordered $\mathrm{Ti}_{3} \mathrm{Al}$ in order to avoid the formation of $\mathrm{Al}-\mathrm{Al}$ bonds. This behaviour is analogous to the formation of superdislocation ribbons in superalloys during the shearing of the ordered $\mathrm{Ni}_{3} \mathrm{Al}$ [41, 42].

[Figure 8 about here.]

[Figure 9 about here.]

Interestingly, the sample aged in the 'short range ordering' region identified by Namboodhiri $\left[13\right.$ ( $\left(625^{\circ} \mathrm{C}\right.$ for 14 days) also showed dislocations travelling in bands and in discrete pairs, Figure 8. Furthermore, additional connections and tangles of the dislocations were observed within the bands. Isolated dislocation pairs could also be observed between the bands.

A variable spacing between dislocation pairs were observed in Ti-6Al-4V aged for 5 weeks at $500^{\circ} \mathrm{C}$ by Wu et al., [39] and this was explained by appealing 
to a random distribution of ordered precipitates. The observation of planar slip and dislocation pairing is consistent with both first and second order long range ordering, and with short range ordering, which of these in fact occurs remains a topic of active study in the community. Although the observation of superlattice spots in certain imaging conditions (Figure 6) suggest that long range ordering does in fact occur. Some authors suggest that composition islands may be detectable in certain circumstances by atom probe tomography [39], although this observation has not been widely reproduced.

The Stroh-like model for dwell fatigue [43, 44, 45, suggests that localised slip band formation in a 'soft' grain well oriented for $\langle a\rangle$ slip initiates the formation of a near-featureless dwell fatigue facet in an adjacent 'hard' oriented grain with its $\{0002\}$ plane near-parallel to the loading axis, via a combination of prism $\langle a\rangle$ slip systems. This explains why macrozones - alternate regions of similarly oriented grains inherited from the transformed $\beta$ colonies - give rise to poor dwell performance, as they produce many such combinations of adjacently oriented grains. It also explains why ordering gives rise to cold dwell fatigue, as ordering would promote the formation of such localised slip band 285 formation. The present work demonstrates that the changes in deformation mechanisms, and single crystal moduli, produced by ordering do not change the overall strain distributions measured in different grain orientations, despite the changes observed in the TEM. Thus, the effect of ordering on dwell fatigue appear to be a consequence of the localisation of deformation and not via any 290 secondary effects, such as hardening due to the precipitation of $\alpha_{2}$, or a change in the overall extent of plastic or elastic anisotropy.

\section{Conclusions}

The microstrain evolution between grain families in a Ti-7Al (wt.\%) alloy during room temperature tensile testing of different heat treated specimens has 295 been investigated using neutron diffraction. For samples after heat treated for 14 days at $625^{\circ} \mathrm{C}$ and 28 days at $550{ }^{\circ} \mathrm{C}$, both the diffraction evidence and dislocation behaviour was consistent with the presence of ordering. The following conclusions can be drawn:

1. Superlattice reflections were visible in diffraction patterns after 14 days of

300 exposure at $625^{\circ} \mathrm{C}$ and 28 days of exposure at $550^{\circ} \mathrm{C}$. Ordered regions could not be observed using dark field imaging.

2. Previous results [40, 17] suggesting that the strength of the superlattice reflections increases with ageing time, are confirmed. This suggested the development of ordering with time within the alloy.

3053 . A slight reduction in the measured $d_{0}$ values and $c / a$ was observed with ageing. Very little or no change in the $\alpha$ phase diffraction elastic constants could be measured.

4. The residual lattice strains observed in the samples aged to different ordering degrees were, to within experimental uncertainty, the same.

3105 . Planar slip bands with dislocation pairs were observed in samples which were aged for 28 days at $550^{\circ} \mathrm{C}$ and 14 days at $625^{\circ} \mathrm{C}$. Such behaviour may be the 
consequence of the formation of different size distributions of $\alpha_{2}$ precipitates. The samples aged at the higher temperature had less well organised arrays of dislocations.

Finally it is concluded that the changes in deformation mechanisms consequent to ordering do not have an effect on the deformation behaviour at the level of grain averages, but only at the level of strain localisation within grains.

\section{Acknowledgements}

Funding for AR was provided by a Rolls-Royce - EPSRC CASE conversion. DD was funded by EPSRC (EP/H004882/1 and EP/K034332/1). Helpful discussions on the TEM aspects are acknowledged with Prof. Mike Loretto, Theresa Morris and Bo Pang at the University of Birmingham. Experimental assistance from Dr Mezan Rahman and Dr Vassilli Voronstov gratefully acknowledged. Material for the study was

325 provided by Timet Whitton (Paul Garratt). Research conducted at ORNL's Spallation Neutron Source was sponsored by the Scientific User Facilities Division, Office of Basic Energy Sciences, US Department of Energy.

\section{References}

\section{References}

330 [1] R. Boyer, Titanium for aerospace: Rationale and applications, Advanced Performance Materials 2 (1995) 349-368.

[2] R. Boyer, Attributes, characteristics, and applications of titanium and its alloys, JOM 62 (2010) 21-24.

[3] R. Boyer, An overview on the use of titanium in the aerospace industry, Materials Science and Engineering A 213 (1996) 103-114.

[4] D. Banerjee, J. Williams, Perspectives on titanium science and technology, Acta Materialia 61 (2013) 844-879.

[5] W. Evans, Optimising mechanical properties in alpha+beta titanium alloys, Materials Science and Engineering 243 (1998) 89-96.

[6] E. Collings, Materials properties handbook: Titanium alloys, ASM International, 1994.

[7] C. Leyens, M. Peters, Titanium and titanium alloys, John Wiley and Sons, 2003.

[8] G. Lütjering, J. Williams, Titanium, Springer, 2003. 
[9] F. Dunne, D. Rugg, A. Walker, Lengthscale-dependent, elastically anisotropic, physically-based hcp crystal plasticity: Application to colddwell fatigue in Ti alloys, International Journal of Plasticity 23 (2007) 1061-1083.

[10] T. Namboodhiri, C. McMahon, H. Herman, Decomposition of the $\alpha$-phase in titanium-rich Ti-Al alloys, Metallurgical Transactions 4 (1973) 13231331 .

[11] M. Blackburn, The ordering transformation in titanium:aluminium alloys containing up to 25 at. pct. Al, Transactions of the Metallurgical Society of AIME 239 (1967) 1200-1208.

[12] N. Thirumalai, Low temperature creep of titanium alloys: Microstructure, deformation mechanisms and modeling, Ph.D. thesis, The Ohio State University, 2000.

[13] T. Namboodhiri, On the Ti-Al phase diagram, Materials Science and Engineering 57 (1983) 21-22.

[14] T. Neeraj, D. Hou, G. Daehn, M. Mills, Phenomenological and microstructural analysis of room temperature creep in titanium alloys, Acta Materialia 48 (2000) 1225-1238.

[15] T. Neeraj, M. Mills, Short-range order (SRO) and its effect on the primary creep behavior of a Ti-6wt.\% Al alloy, Materials Science and Engineering A 319-321 (2001) 415-419.

[16] H. Wood, G. Smith, A. Cerezo, Short range order and phase separation in Ti-Al alloys, Materials Science and Engineering A 250 (1998) 83-87.

[17] H. Liew, Short range order and phase separation in Ti-Al alloys, Ph.D. thesis, University of Oxford, 1999.

[18] M. Blackburn, J. Williams, Metallurgical aspects of the stress corrosion cracking of titanium alloys, in: Proceedings of conference on fundamental aspects of stress corrosion cracking, 1969, pp. 620-637.

[19] D. Gloaguen, G. Oum, V. Legrand, J. Fajoui, S. Branchu, Experimental and theoretical studies of intergranular strain in an alpha titanium alloy during plastic deformation, Acta Materialia 61 (2013) 5779-5790.

[20] J. Cho, D. Dye, K. Conlon, M. Daymond, R. Reed, Intergranular strain accumulation in a near-alpha titanium alloy during plastic deformation, Acta Materialia 50 (2002) 4847-4864.

[21] J. Warwick, J. Coakley, S. Raghunathan, R. Talling, D. Dye, Effect of texture on load partitioning in Ti-6Al-4V, Acta Materialia 60 (2012) 41174127. 
[22] A. Stapleton, S. Raghunathan, I. Bantounas, H. Stone, T. Lindley, D. Dye, Evolution of lattice strain in Ti-6Al-4V during tensile loading at room temperature, Acta Materialia 56 (2008) 6186-6196.

[34] W. Bell, W. Roser, G. Thomas, Diffraction analysis of dislocation pairs for detecting order in solid solutions, Acta Metallurgica 12 (1964) 1247-1253. 
[36] D. Williams, B. Carter, Transmission electron microscopy, volume 2nd Edition, Springer, 2009.

[37] M. Brandes, Creep, fatigue and deformation of $\alpha$ and $\alpha-\beta$ titanium alloys at ambient temperature, Ph.D. thesis, The Ohio State University, 2008.

[38] U. Lienert, M. Brandes, J. Bernier, J. Weiss, S. Shastri, M. Mills, M. Miller, In situ single-grain peak profile measurements on Ti-7Al during tensile deformation, 2009524 (Materials Science and Engineering: A) 46-54.

[39] Z. Wu, C. Qiu, V. Venkatesh, H. Fraser, R. Williams, G. Viswanathan, M. Thomas, S. Nag, R. Banerjee, M. Loretto, The influence of precipitation of $\alpha_{2}$ on properties and microstructure in TIMETAL 6-4, Metallurgical and Materials Transactions A 44 (2013) 1706-1713.

[40] H. Liew, G. Smith, A. Cerezo, D. Larson, Experimental studies of the phase separation mechanism in Ti-15 at.\%Al, Materials Science and Engineering: A 270 (1998) 9-13.

[41] C. Rae, R. Reed, Primary creep in single crystal superalloys: Origins, mechanisms and effects, Acta Materialia 55 (2007) 1067-1081.

[42] V. Vorontsov, R. Voskoboinikov, C. Rae, Shearing of $\gamma^{\prime}$ precipitates in Nibase superalloys: a phase field study incorporating the effective $\gamma$-surface, Philosophical Magazine 92 (2012) 608-634.

[43] V. Hasija, S. Ghosh, M. Mills, D. Joseph, Deformation and creep modeling in polycrystalline Ti-6Al alloys, Acta Materialia 51 (2003) 4533-4549.

[44] W. Evans, M. Bache, Dwell-sensitive fatigue under biaxial loads in the nearalpha titanium-alloy IMI685, International Journal of Fatigue 16 (1994) $443-452$.

[45] F. Dunne, A. Walker, D. Rugg, A systematic study of hcp crystal orientation and morphology effects in polycrystal deformation and fatigue, Proceedings of the Royal Society A 463 (2007) 1467-1489.

[46] L. Swartzendruber, L. Bennett, L. Ives, R. Shull, The Ti-Al phase diagram: the $\alpha-\alpha_{2}$ phase boundary, Materials Science and Engineering 51 (1981) 1-9. 


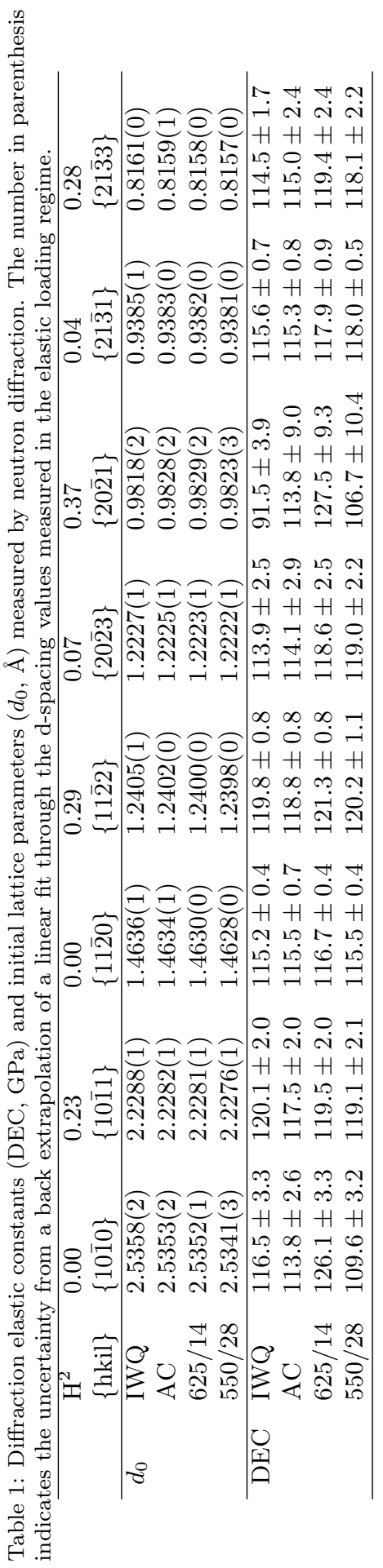


450 List of Tables

455

1 Diffraction elastic constants (DEC, GPa) and initial lattice parameters $\left(d_{0}, \dot{A}\right)$ measured by neutron diffraction. The number in parenthesis indicates the uncertainty from a back extrapolation of a linear fit through the d-spacing values measured in the elastic loading regime. . . . . . . . . . . . . . . . . 13

2 Young's modulus, E (GPa) for IWQ, AC, 625/14, and 550/28

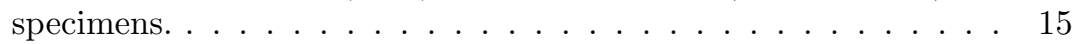


Table 2: Young's modulus, E (GPa) for IWQ, AC, 625/14, and 550/28 specimens.

\begin{tabular}{lll}
\hline & $E, \mathrm{GPa}$ & $c / a$ \\
\hline IWQ & $105.2 \pm 1.0$ & $1.6949(3)$ \\
$\mathrm{AC}$ & $109.7 \pm 0.7$ & $1.6947(2)$ \\
$625 / 14$ & $108.3 \pm 0.8$ & $1.6945(4)$ \\
$550 / 28$ & $114.4 \pm 0.8$ & $1.6947(2)$ \\
\hline
\end{tabular}




\section{List of Figures}

460

11 (a) Phase diagram for the Ti-Al system [10, 46, 11, adapted from [13]. The experimental heat treatments used in the present study are identified. (b) Recrystallised microstructure in the Ti-7Al

bar. (c) Electron backscatter diffraction map with IPF coulouring relative to the normal direction (ND). Indexing rate $97 \%$ using a

465 step size of $0.4 \mu \mathrm{m}$. (d) Texture pole figure from an area of $2500 \times$ $2000 \mu \mathrm{m}$, with $4.5 \mu \mathrm{m}$ step size; $\sim 4000$ grains. The transverse directions $\left(\mathrm{TD}_{1}\right.$ and $\left.\mathrm{TD}_{2}\right)$ of the bar are marked. . . . . . . . 17

2 (a) A schematic of the experimental setup on the VULCAN instrument at the Spallation Neutron Source at ORNL, TN, USA

470 (top view, not to scale). (b) Intensity against d-spacing for Ti-7Al

in the IWQ condition at 20MPa in the loading direction (longitudinal detector L). Inset shows the corresponding fit to the experimental data for the $\{1120\}$ peak. $\ldots \ldots \ldots \ldots$

3 (a) Applied stress versus lattice strain graph from $\{11 \overline{2} 0\}$ in the loading direction. (b) Tensile loading curves for the four condi-

475 tions examined. Beyond the yield point, samples were periodically unloaded and measurments were taken at $620 \mathrm{MPa}$ (unloads removed for clarity). $\ldots \ldots \ldots \ldots \ldots \ldots \ldots \ldots$

a 4 Residual lattice strain evolution as a function of plastic strain in

40 the loading direction. Typical peak fitting uncertainties for each peak are indicated by the error bars provided. Trendlines were inserted to data as guides to the eye. . . . . . . . . . . 20

5 Residual lattice strain inverse pole figure (in the loading direction) for the different samples examined, averaged over the inter-
val between 2 and $4 \%$ plastic strain. The contours are guides to

485

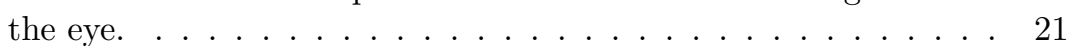

\begin{tabular}{|l|ll}
\hline & $\{2110\}$ diffraction patterns showing the effect of ageing time and
\end{tabular} temperature on the observation of superlattice reflections; (a)IWQ, (b)AC, (c) $625 / 14$, (d) 550/28. The intensity scale has been inverted to highlight the superlattice reflections (marked by arrows). 22

490

7 Dislocation configuration in the air cooled (AC) sample, after deformation to $4.5 \%$ plastic strain. $\ldots \ldots \ldots \ldots \ldots . \ldots \ldots$

8 Dislocation configuration in the sample aged at $625^{\circ} \mathrm{C}$ for 14 days, after straining $4.5 \%$ plastic strain. An example of paired dislocations is indicated by the blue arrow. . . . . . . . . . 24

495

$9 \quad$ Dislocation pairs observed in the sample aged at $550^{\circ} \mathrm{C}$ for 28 days, after straining to $4.5 \%$ plastic strain in tension. An example of paired dislocations is indicated by the blue arrow. . . . . . . . 25 


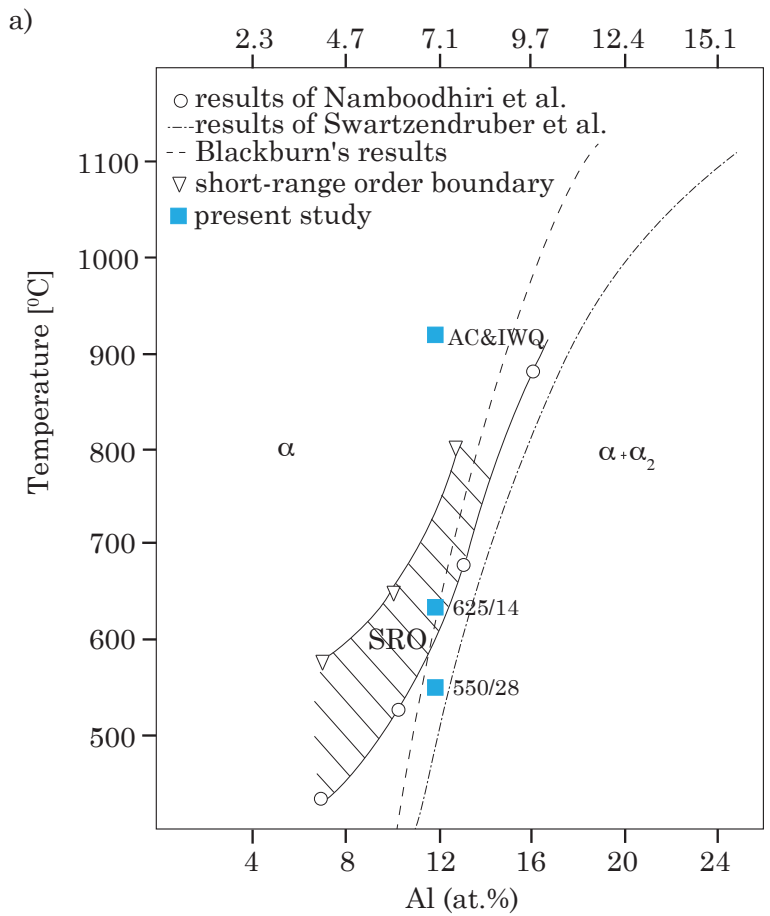

b)

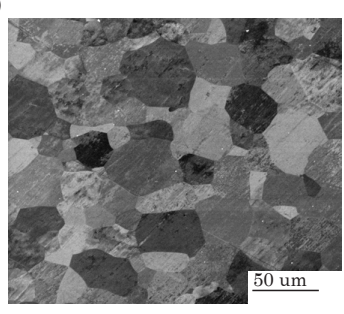

c)

d)
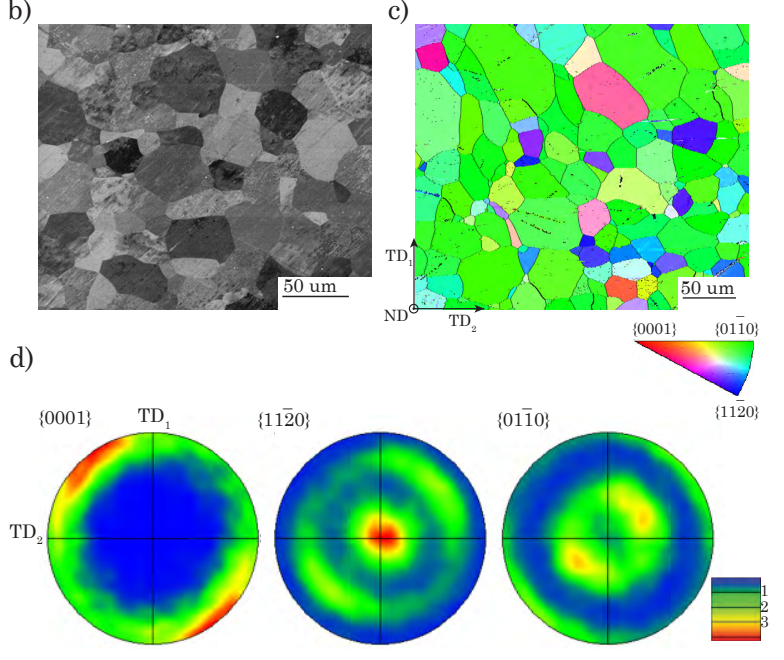

Figure 1: (a) Phase diagram for the Ti-Al system [10, 46, 11, adapted from 13. The experimental heat treatments used in the present study are identified. (b) Recrystallised microstructure in the Ti-7Al bar. (c) Electron backscatter diffraction map with IPF coulouring relative to the normal direction (ND). Indexing rate $97 \%$ using a step size of $0.4 \mu \mathrm{m}$. (d) Texture pole figure from an area of $2500 \times 2000 \mu \mathrm{m}$, with $4.5 \mu \mathrm{m}$ step size; $\sim 4000$ grains. The transverse directions $\left(\mathrm{TD}_{1}\right.$ and $\left.\mathrm{TD}_{2}\right)$ of the bar are marked. 
a)

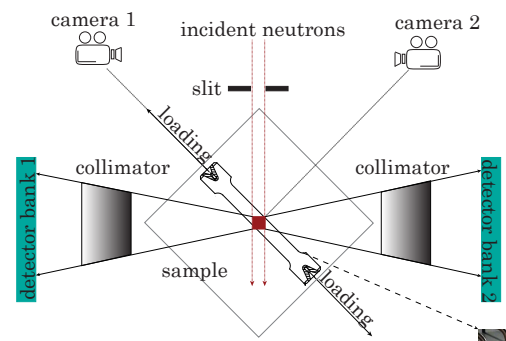

b)
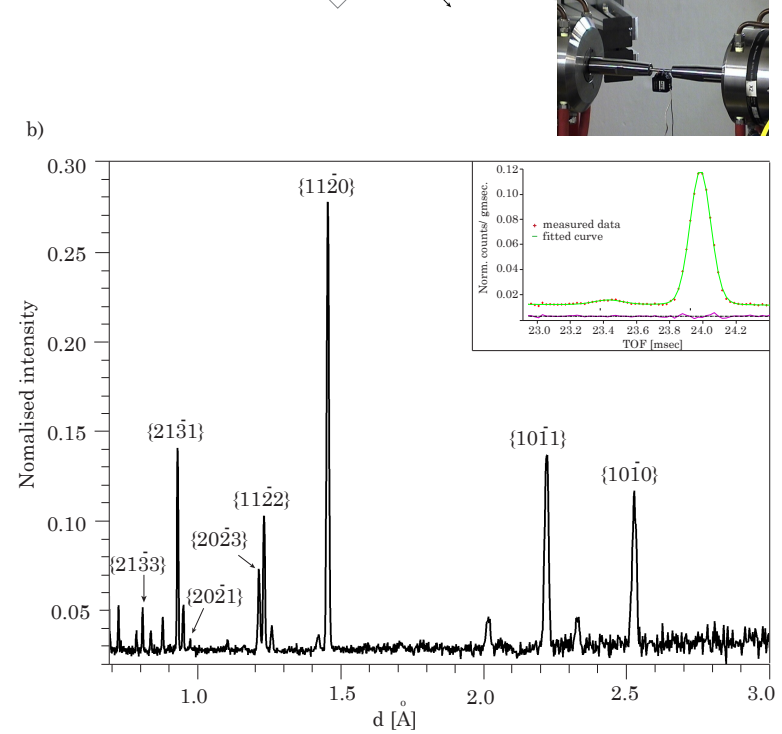

Figure 2: (a) A schematic of the experimental setup on the VULCAN instrument at the Spallation Neutron Source at ORNL, TN, USA (top view, not to scale). (b) Intensity against d-spacing for $\mathrm{Ti}-7 \mathrm{Al}$ in the IWQ condition at $20 \mathrm{MPa}$ in the loading direction (longitudinal detector L). Inset shows the corresponding fit to the experimental data for the $\{11 \overline{2} 0\}$ peak. 

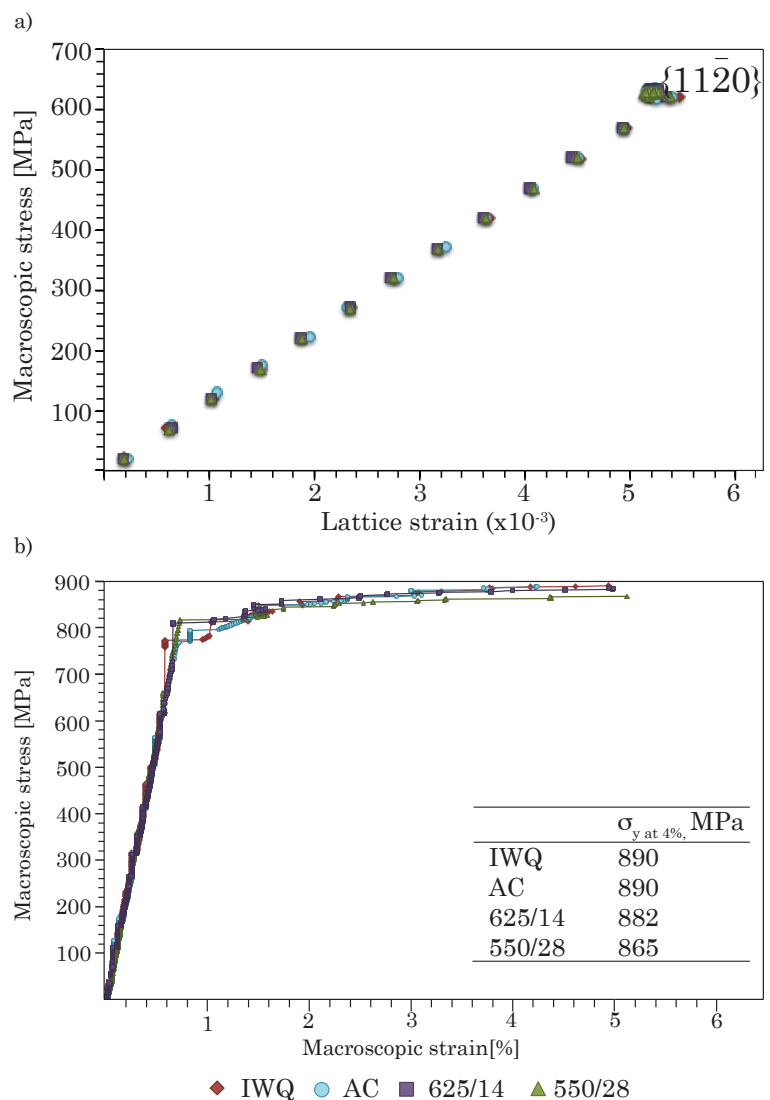

Figure 3: (a) Applied stress versus lattice strain graph from $\{11 \overline{2} 0\}$ in the loading direction. (b) Tensile loading curves for the four conditions examined. Beyond the yield point, samples were periodically unloaded and measurments were taken at $620 \mathrm{MPa}$ (unloads removed for clarity). 

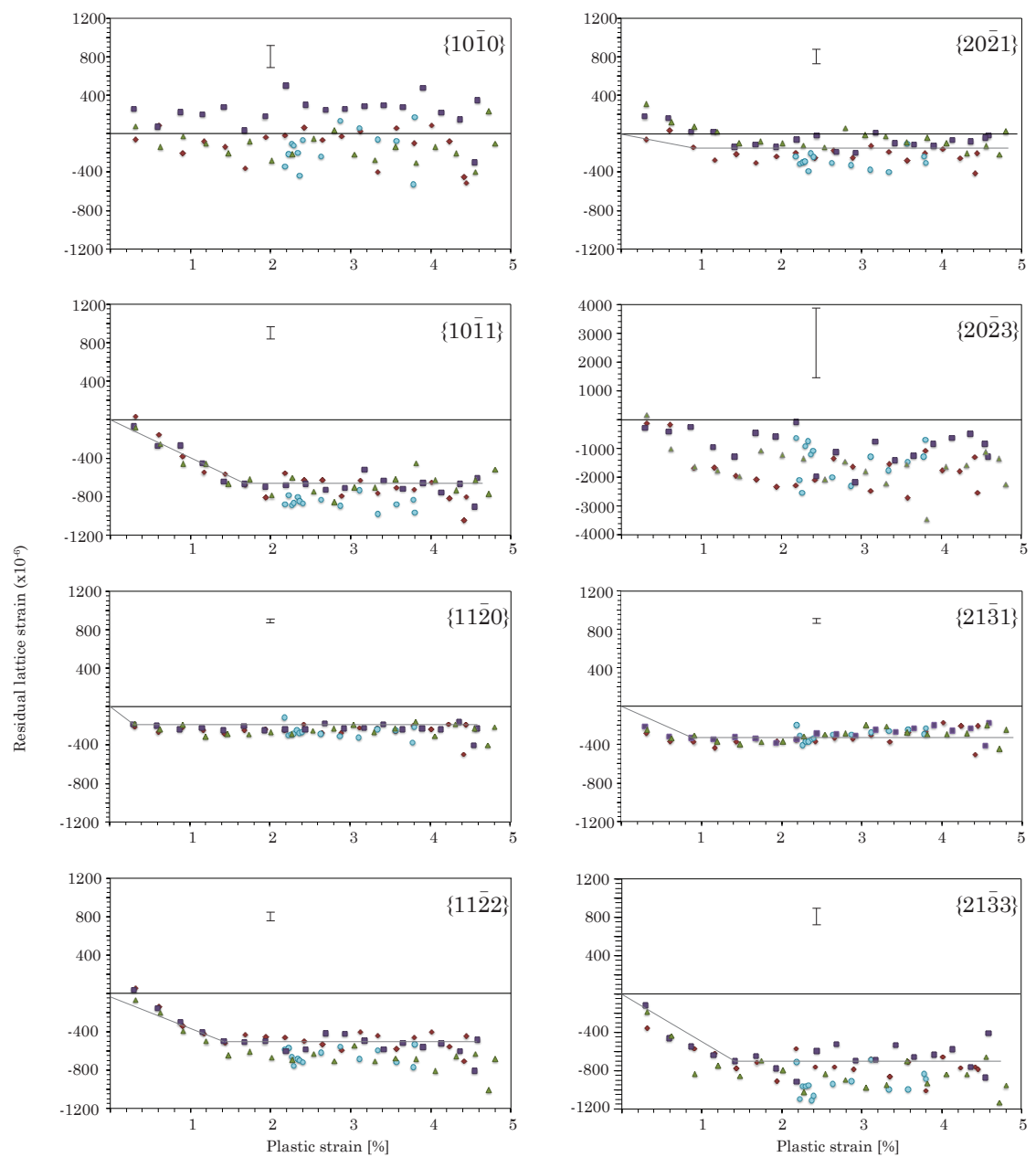

- $\mathrm{IWQ} \circ \mathrm{AC} \backsim 625 / 14 \quad \Delta 550 / 28$

Figure 4: Residual lattice strain evolution as a function of plastic strain in the loading direction. Typical peak fitting uncertainties for each peak are indicated by the error bars provided. Trendlines were inserted to data as guides to the eye. 


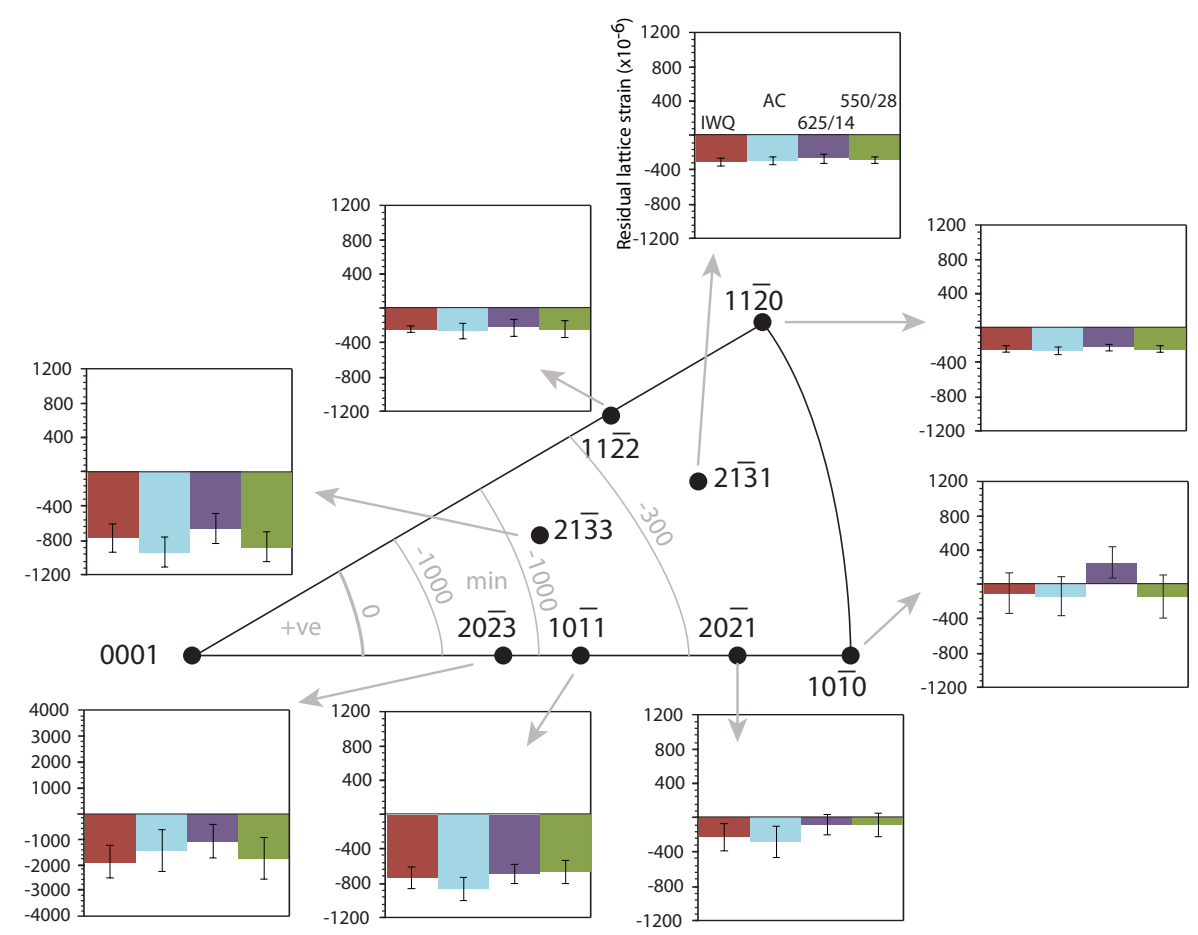

Figure 5: Residual lattice strain inverse pole figure (in the loading direction) for the different samples examined, averaged over the interval between 2 and $4 \%$ plastic strain. The contours are guides to the eye. 
a)

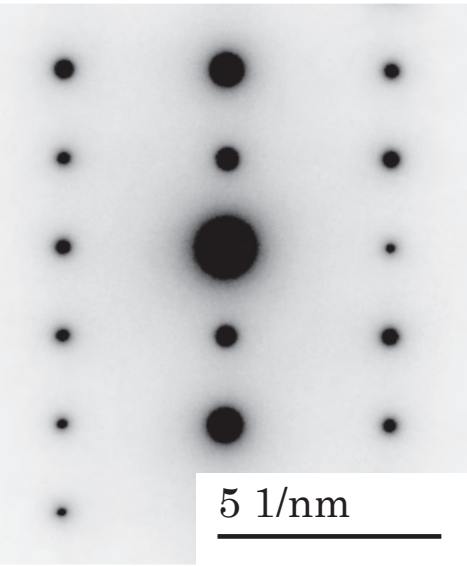

c)

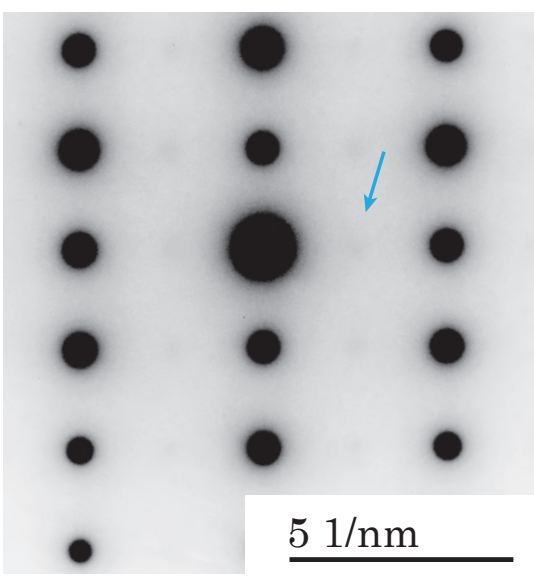

b)

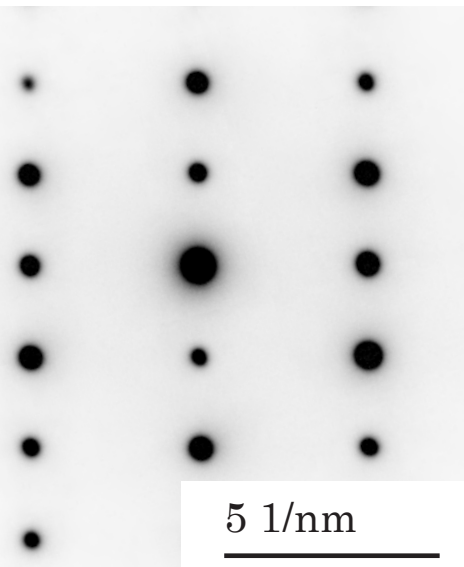

d)

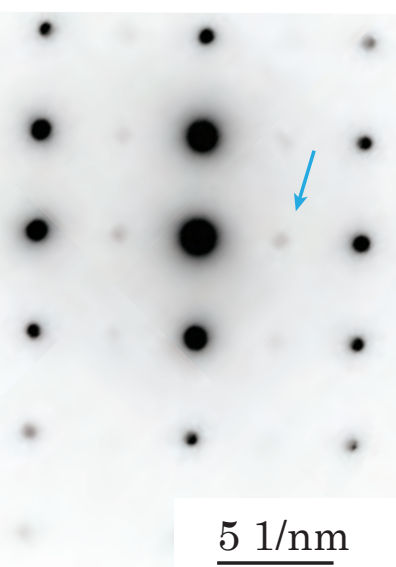

Figure 6: $\{2 \overline{1} \overline{1} 0\}$ diffraction patterns showing the effect of ageing time and temperature on the observation of superlattice reflections; (a)IWQ, (b)AC, (c) 625/14, (d) 550/28. The intensity scale has been inverted to highlight the superlattice reflections (marked by arrows). 
a)

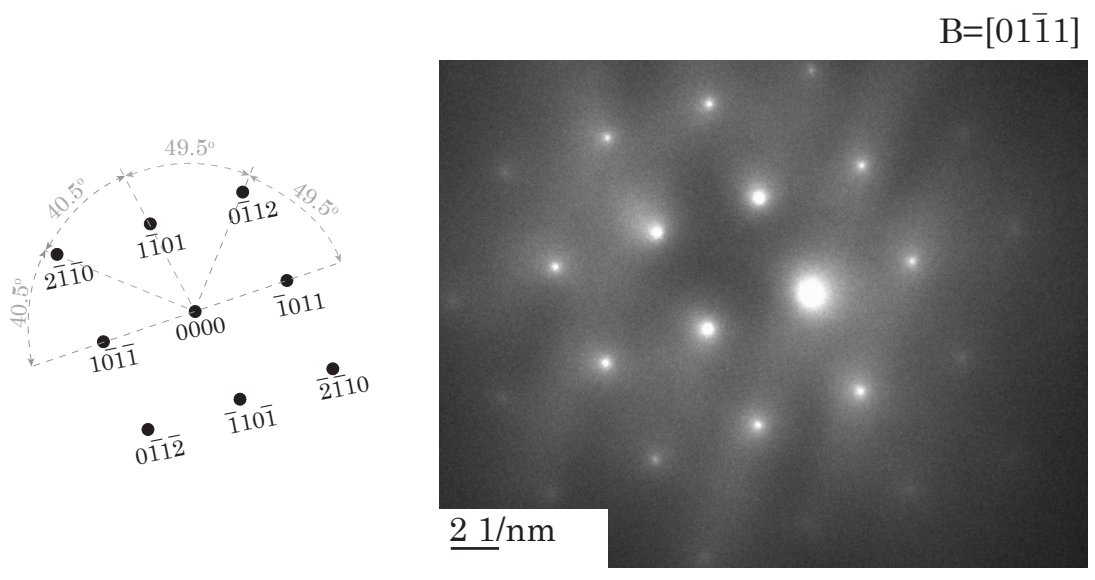

c)

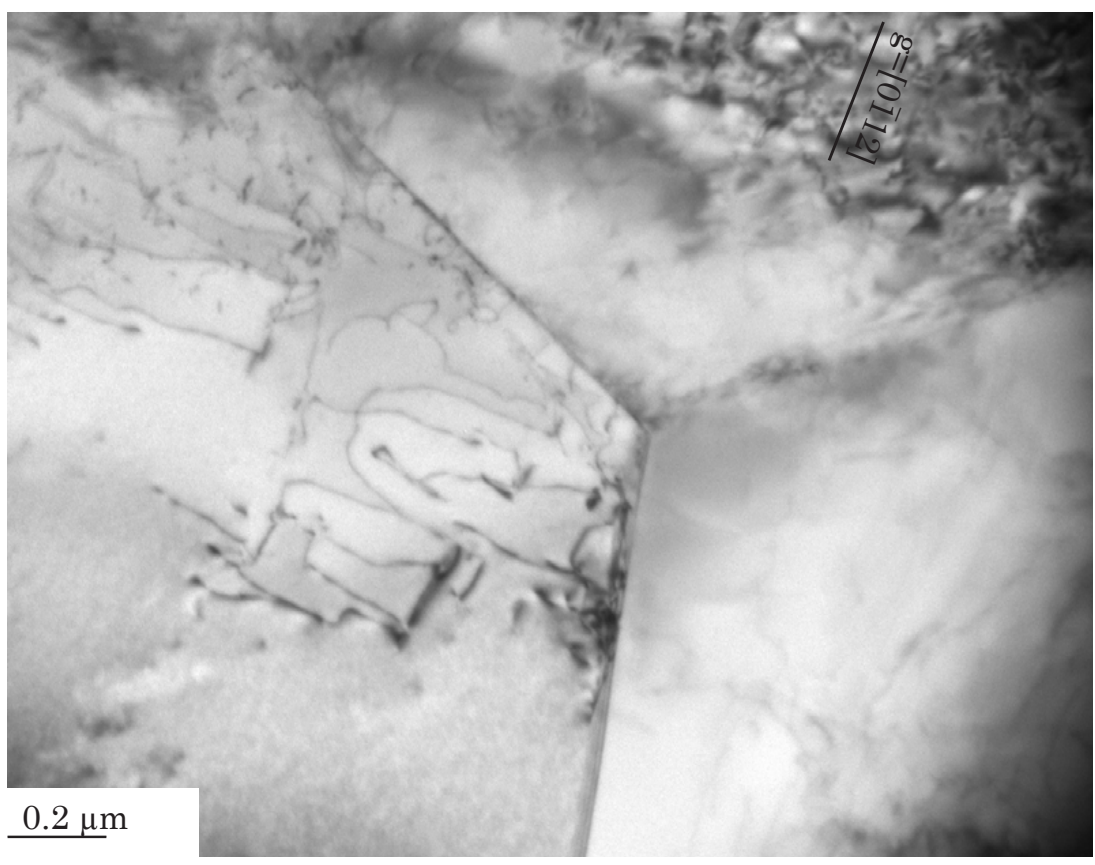

Figure 7: Dislocation configuration in the air cooled (AC) sample, after deformation to $4.5 \%$ plastic strain. 
a)

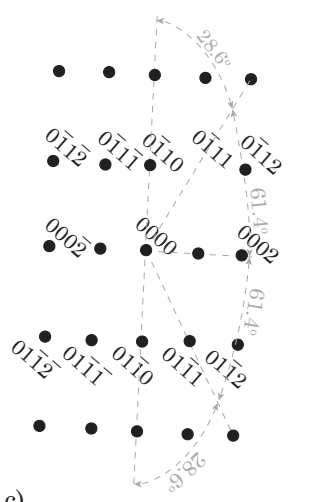

b)

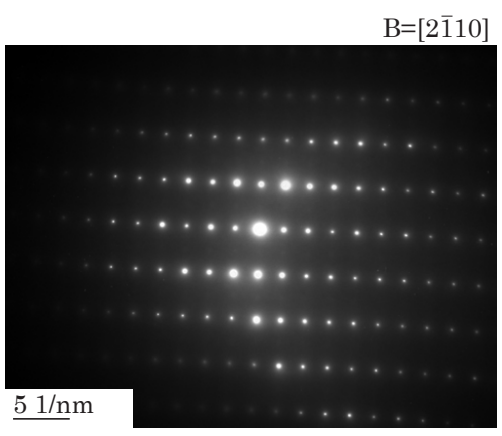

c)

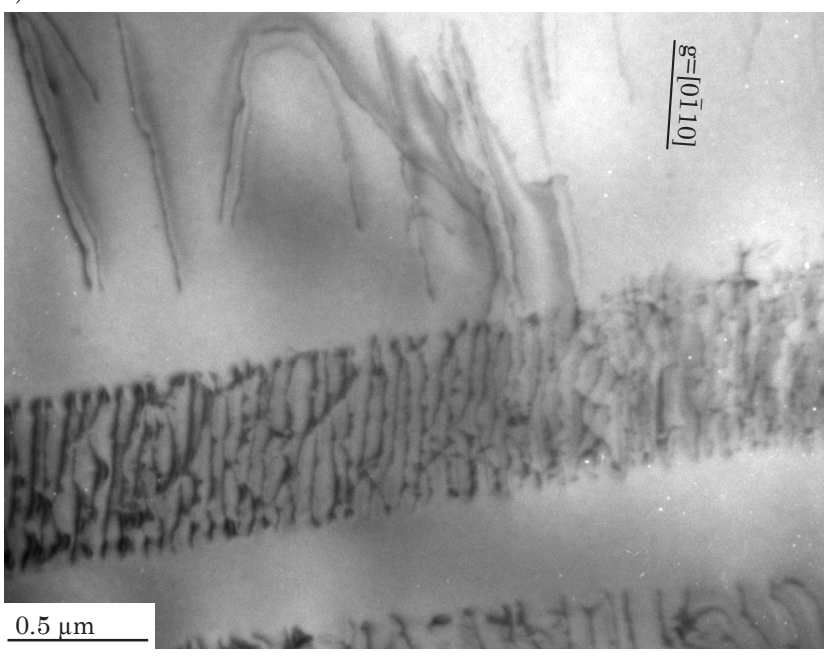

d)

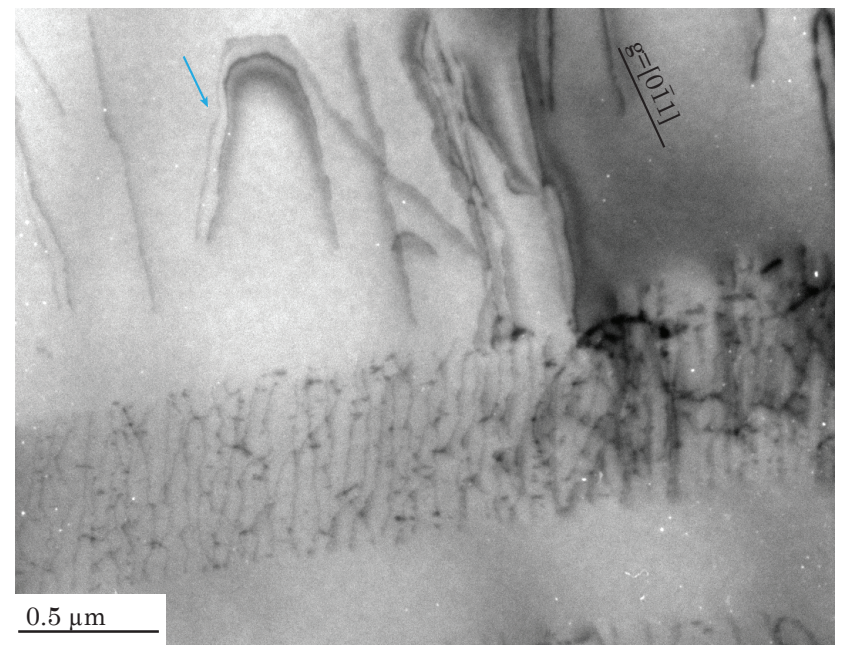

Figure 8: Dislocation configuration in the sample aged at $625^{\circ} \mathrm{C}$ for 14 days, after straining $4.5 \%$ plastic strain. An example of paired disßkations is indicated by the blue arrow. 
a)

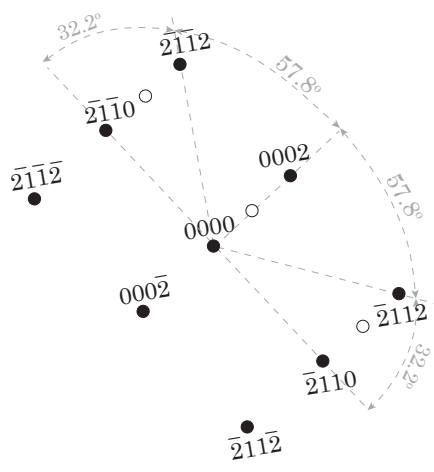

b)

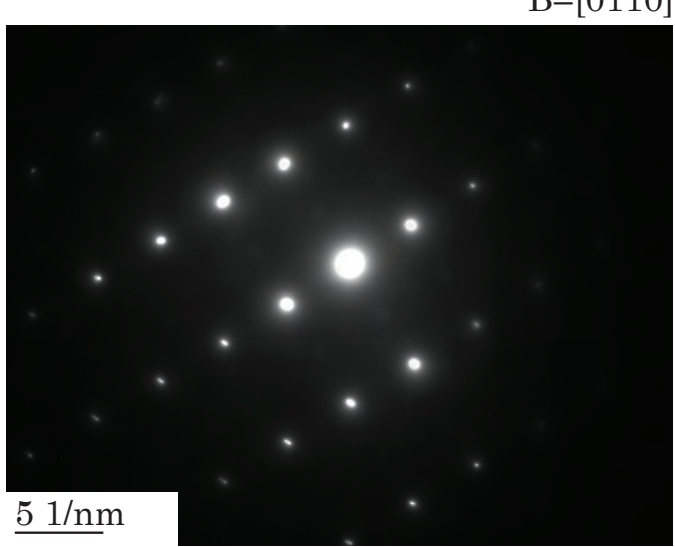

c)

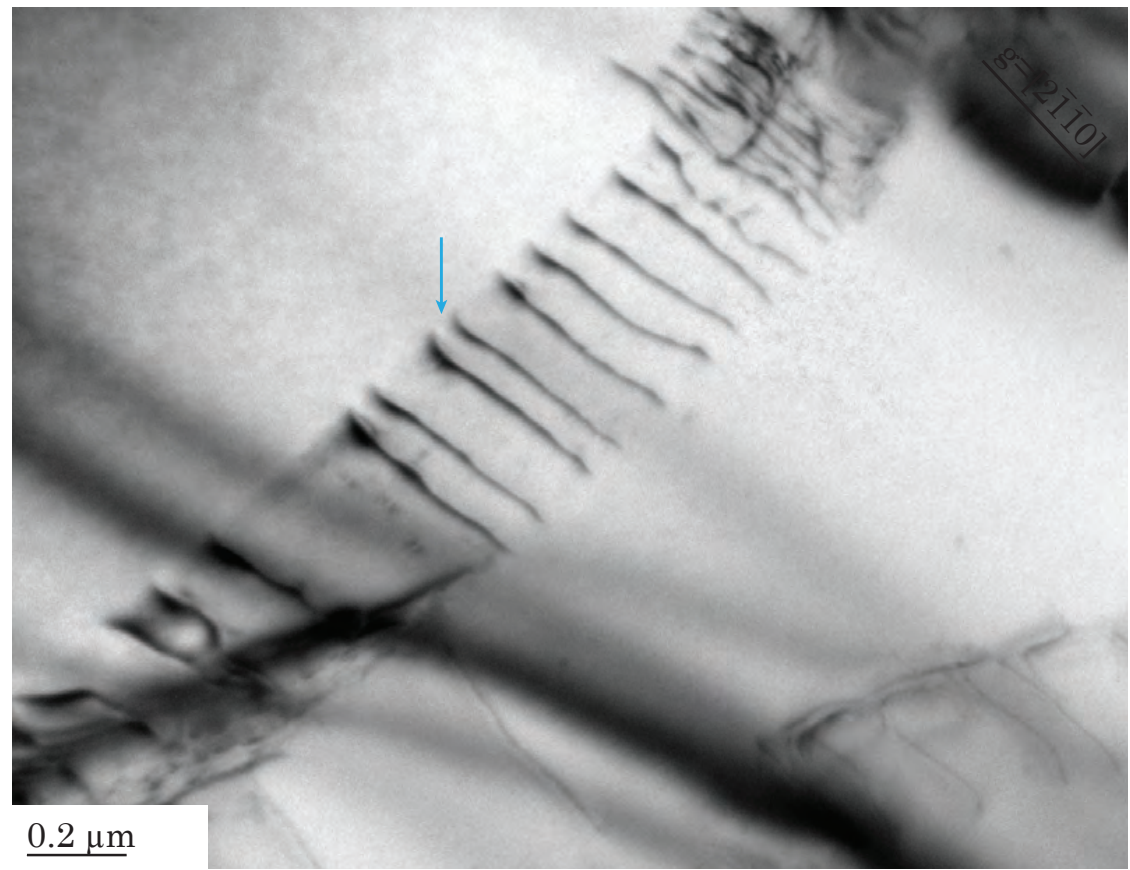

Figure 9: Dislocation pairs observed in the sample aged at $550{ }^{\circ} \mathrm{C}$ for 28 days, after straining to $4.5 \%$ plastic strain in tension. An example of paired dislocations is indicated by the blue arrow. 